\title{
$\angle$ Research Square \\ Seismic Evidence of Pop-up Tectonics Beneath the Shillong Plateau Area of Northeast India
}

\section{A. P. Singh ( $\sim$ apsingh07@gmail.com )}

\author{
Ministry of Earth Sciences
}

O. P. Mishra

Ministry of Earth Sciences

O. P. Singh

Geological Survey of India

\section{Research Article}

Keywords: Pop-up, Seismic Structure, Plateau and Seismicity; Major Earthquakes

Posted Date: January 11th, 2022

DOI: https://doi.org/10.21203/rs.3.rs-1222223/v1

License: (1) This work is licensed under a Creative Commons Attribution 4.0 International License.

Read Full License

Version of Record: A version of this preprint was published at Scientific Reports on August 19th, 2022.

See the published version at https://doi.org/10.1038/s41598-022-18389-0. 


\section{Abstract}

Our detailed analysis of high-quality arrival time data recorded by the local seismographic network using three-dimensional seismic tomography of the Shillong Plateau region using high-quality arrival times of the body wave phases recorded at a dense temporary seismic network. This technique is used to understand the heterogeneities of the crust and its implications for pop-up tectonics characterizing evaluation the of the Shillong Plateau. We investigated an area covering $\sim 150 \times 100 \mathrm{~km}^{2}$ that revealed seismicity to be confined in a depth range $\leq 60 \mathrm{~km}$. High - velocity anomalies in the upper crust appear to be responsible for intense small to moderate seismic activity in the region. Crustal seismic velocities inferred from 3-D seismic tomography showed significant lateral heterogeneities beneath the lithosphere of the Shillong Plateau. High-velocity anomalies in the uppermost crust, interpreted as the Shillong Plateau act as a geometric asperity where interseismic strain may accumulate. Low-velocity anomalies in the lower crust probably play a major role to accommodating the stresses generated due to plate separation, culminating in future sources of great earthquakes. The geological faults are well imaged in the cross-sections and support the concept of Pop-up tectonics beneath the Shillong of NE India.

\section{Introduction}

The Shillong Plateau is a unique portion in the Precambrian history of the Indian shield that is detached from the peninsular shield during the Miocene, and moved horizontally by $\sim 300 \mathrm{~km}$ eastwards along the E-W trending Dauki fault (Evans, 1964). It lies at the boundary of the Himalayan arc to the north and the Burmese arc to the east. The Shillong Plateau is separated by the Dauki Fault (DKF) from thick Tertiary sediments of the Bengal basin in the south (Fig. 1). This plateau also overthrusts the Bengal Basin from the north (Johnson and Nur Alam, 1991).The plateau, however, separates from the Himalayas in the north by the Brahmaputra River. The prominent E-W, N-S and NW-SE trending faults associated with the Shillong Plateau reflect complexity in the seismotectonics of the region (Fig. 1), which is still geophysically and seismologically less investigated due to the inaccessibility of this region. The plateau has attracted many geoscientists because of its unique location, complex geotectonic settings, frequency occurrence of earthquakes, a series of past damaging and nondamaging earthquakes and its continental type of structure.

The Shillong Plateau is a pop-up system confined by two reverse faults a hidden Oldham fault (OF)in the north and a DKF in the south (Bilham and England, 2001; Nayak et al., 2008). The fault bounding pop-up structure is penetrats the whole crust (Bilham and England, 2001). Earlier investigations in the study region were based on either limited datasets for the limited period or regional data collected from the seismological catalogues ascribed to the International Seismological Centre [ISC] (Sitaram, 1986; Kayal and De, 1987; Mukhopadhaya et al., 1995; Mishra, 2004).The ISC data have neither available small earthquake parameters nor accuracy for direct or converted phase arrivals. Really, thanks for this opportunity to perform 3-D seismic tomography study to image the Shillong Plateau with high quality data sets recorded at good azimuthal coverage seismic network. Adjacent to the study region in the Brahmaputra, less the seismicity has also not been witnessed from any great earthquake in the past. 
Thus, the complexity of tectonics could play a significant role for accommodating stress and plate separation and causing earthquakes.

The Shillong Plateau experienced a great earthquake $\left(M_{s} 8.7\right.$; revised $\left.M_{w} 8.1\right)$ on June 12, 1897, which caused catastrophic damage to life and property in the region (Oldham 1899; Rao, 1953; Ben-Menahem et al., 1974; Bilham and England, 2001). This great earthquake occurred on the detachment, and the rupture propagated to the south (Seeber and Armbruster, 1981). Kayal et al., 1987 used limited data sets recorded in a limited seismic network to determine the 3-D seismic structure of the region. However, due to complexity in the perspective of seismotectonics and geodynamics, no one is able to provide a single tectonic model to explain the complex structure and occurrence of shallow and scattered earthquakes (Fig. 1) for this region (Holt et al, 1991; Kayal, 2001; Gahalaut et al., 2011; Gahalaut and Kundu, 2012). It also appears that this plateau, although it generated a large earthquake in the past, is quite poorly understood due to the paucity of data arising from the inadequate deployment of seismological networks in this region. The earthquake patterns are quite different in the western and eastern portions, however, the overall seismic activity of the region may be assumed to depend on the stress generated and resistance offered by compression from all sides in the regions. Despite several studies conducted in the study region (e.g., Kayal et al., 1987; Srivastava et al., 1996; Gahalaut et al., 2011;Kayal et al., 2012; Bora et al., 2018), no common consensus has yet been cropped out to address the key issue of the active seismogenesis of the plateau and its area. There is also still a common consensus over the origin and existence of the Oldham fault and pop theory proposed by Bilham and England, 2001. The assimilated three-dimensional seismic structures of the Shillong Plateau derived from high-quality $P$ - and $S$ wave arrival time data from precisely and closely located earthquakes recorded at dense seismographs yield reliable crustal models and allow us to answer several outstanding questions in the study region.

\section{Results}

The results of the synthetic test suggest that the checkerboard pattern is well recovered alternatively for both Vp- and Vs- structures for all depth levels because of the concentration of high-quality data recorded at a dense seismic network that causes a high density of ray coverage at all depths as evident from hit count tests. However, the velocity images $(V p, V s)$ and Poisson's ratio $(\sigma)$ also have comparatively lower resolution for velocity images assimilated for 50 - and $60-\mathrm{km}$ depth layers because of lower the number of events from these layers, reducing hit counts at these depths. Tomographic inversions and resolution tests with different grid spacings, initial velocity models, and datasets were also performed and show that the seismic velocity anomalies discussed above beneath the study region can be resolved well. We also conducted several changes in the velocity gradient and velocity values of the starting model. Although there were some small changes in the amplitude of the velocity anomalies $(<1.0 \%)$, the patterns of the tomographic images were generally the same. The overall patterns of the Vp and Vs images are similar, but there are some differences in details.

The seismicity in the study area is mostly confined within the middle portion in two seismically active segments: N-S trending along the Dudhnoi fault and NE-SW trending along the Barapani Thrust. The 
establishment of a denser seismographic network in comparison to the previous study (Kayal and Zhao, 1998) provided significant variations in terms of seismic velocities (Vp and Vs) and Poisson's ratio ( $\sigma$ ) at different depths in the study region that may be related to the subsurface crustal heterogeneities (Fig. 2) that can have appreciable control on the lithostatic stress pattern of the region (Govin et al., 2018).

Figs. $2 a$ and $b$ show the perturbation of P-wave and S-wave velocities in $\%$ at different depth levels. It is clearly observed that the Dauki Fault, Oldham Fault and Barapani thrust are located at the boundaries of low and high velocities. Mostly, seismicity is associated with high-Vp and high Vs- and Low $\sigma$.

We examined vertical cross sections of the seismic velocities (Vp and Vs)and Poisson's ratio ( $\sigma$ ) structures along eight selected profiles, three along the Shillong Plateau (Profiles A-B, C-D, and E-F), eastwest directions (Profiles G-H, I-J, K-L), NW-SE direction (Profile M-N) and NE - SW detection (Profile O-P), which are shown in Fig. 1. We examined these cross sections to understand the lithospheric structures at different depths (Fig. 3-5). Our results reveal strong lateral structural heterogeneities within the top $60 \mathrm{~km}$ in the study area. The broad Vp- and Vs- structures remain the same although some small patterns have changed in all the profiles. These broad crustal layers are also well reflected in the corresponding Vs sections. We examined $\sigma$ cross-sections along the selected profiles (Fig. 1). In the profiles along the study area, we observe a prominent low $\sigma$ zone down to a depth of $40 \mathrm{~km}$. Furthermore, higher $\sigma$ was observed at deeper depths $>40 \mathrm{~km}$. The study areas are, however, well covered by the seismological network; the seismic data produced high-resolution seismic structures (Figs. 4 and 5).A robust feature appears in both Vp- and Vs-cross sections, that is, the Dauki Fault gently dips northward toward high-Vp and Vs and the low $\sigma$ layer beneath the Shillong Plateau down to a depth of $50 \mathrm{~km}$ (Figs. 5- 7). This northwards dip velocity and layers increase gradually and penetrate the uppermost mantle. Such high-velocity layers at deeper depths have been revealed in Himalayan segments (Monsalve et al., 2008). We observed that the earthquakes are mostly confined within a depth of $40 \mathrm{~km}$. It is also noted that there is scattered or less seismic activity at deeper depths. These results indicate rheological changes in the crust at the Moho depth. The high velocity structures are all along the north direction compared to the south direction down. High seismic velocities are identified between two low velocities along cross sections $A B, C D$ and $E F$ and $\mathrm{KL}$ as high velocities compared to the Shillong plateau. High velocities are observed on the western side with a number of smaller magnitude earthquakes in the entire investigation area than in the eastern portion of the surveyed area (Kayal et al., 2011) along cross sections GH, IJ and KL.

All cross sections are considered along the plateau (see the profile locations in Fig. 1); the velocity structures and their bearing on the nature of the lower crust are clearly reflected (Figs. $3-5$ and 7 ). The Vp- and Vs-structures (Figs. 3 - 5) show that high seismic velocity anomalies are bounded by low seismic velocity anomalies, consistent with a Shillong Plateau bounded by the Dauki Fault and Oldham Fault. It may be inferred that the movement along these two faults might be coupled due to differential seismic velocity anomalies in the region, thus turning the local faults and lineaments active and generating seismic activity of smaller magnitudes at shallower depths. It may be stated that a differential stress condition is observed in the entire investigation area, and the western part is less stressed with a number of smaller magnitude earthquakes than the eastern part of the surveyed area (Kayal et al., 2011). Along the profiles (Figs. 3 - 5), the high velocities and zones in the Shillong reflect the plateau and are well 
imaged at depths. The low-Vp and -Vs zones and high ratio at shallower depths (2-10 km) may be attributed to fractures or sediment vertical structures, which are seismically active. In the E-W profiles, the lateral variations in seismic velocities and velocity ratios are more or less similar.

\section{Discussion}

Significant lateral heterogeneities in the velocity structures of the crust and upper mantle beneath the plateau are noticed. The lower velocities in the shallower layers are associated with the near surface geology. The velocity reduction near the surface may result from a combination of high sediment thickness, high pore pressure and active strain. In profile GH, the low velocity zone continues along the Oldham Fault and Barapani Thrust. In the uppermost mantle, a low seismic velocity and $\sigma$ are quite prominent beneath the plateau. The uppermost mantle is not as seismically active as those in the lower crust. The occurrence of earthquakes in the upper crust inferred that high velocity zones are stress accumulators in the strong heterogeneity medium. However, seismic activity along these two faults is not noticed significantly during the study period, and it may be inferred that the movement along these faults might be generating compressional stress in the region, thus gyrating the local faults and lineaments to be active and generating seismic activity of smaller magnitudes at shallower depths. The high velocity bodies beneath the plateau, where mostly seismicity is located, indicate that the seismogenic zone that shows brittle behaviour is thicker in this area than other similar tectonics of the regions. A robustness test for this anomaly, shows a good recovery of the input structure. This plateau is situated over the buckledup part of the Indian lithosphere (Raoof et al., 2017). At depths of approximately 35 to $50 \mathrm{~km}$, there are narrow low velocities and $\sigma$ below the plateau (Figs. 3-5). This could indicate that the top of the buckledup part cracked and was partially undertrusted by low-velocity materials. The low velocity towards the northern part of the region may not put up much resistance to underthrusting leading to less seismic activity there. Within the Shillong Plateau region, N-S trending low Vp, Vs and high-Vp/Vs zones (Figs. 3 -5) could be associated with the Dudhnoi faut and Oldham fault and several lineaments present in this area (Bilham and England, 2001). It is also noticed that an approximately $200 \mathrm{~km}$ long E-W Dauki fault is well imaged, indicating high $-\mathrm{Vp}$ and $-\mathrm{Vs}$ towards the western region and low-Vp and $\mathrm{Vs}$ on the eastern sides (Figs. 3 and 4). This evidence of a subducting Indian plate is noticeably imaged as high velocities and low $\sigma$. It is striking that these seismic velocity structure variations in the crust are localized and isolated. The great earthquakes that occur in the upper crust suggest that a strong anisotropy is developed in response to the shear processes responsible for the occurrence of great earthquakes in that sector of the Shillong Plateau. The high velocity zones mark areas that are lacking in seismicity. Beyond $60 \mathrm{~km}$, we have no better resolution of the assimilated seismic structures because of the reduced spatial distribution of crisscrosses among seismic rays at deeper depths (Fig. 8). Despite the high tectonic complexity of the region, some correlation may be highlighted between geological units and velocity structures. In some of the profiles, the high velocities and low $\mathrm{Vp} / \mathrm{Vs}$ ratio penetrate the upper crust and dip northwards, where the thickness of the crust varies vigorously. Consequently, the low $\sigma$ perturbations suggest that the low value could have been due to fewer pores and competent rock, which can store stress accumulation to a greater extent. On the other hand, the higher values of $\sigma$ in the lower crust or in 
some patches may suggest relatively weaker rocks of the subsurface, which can undergo metamorphism processes at deeper layers under suitable pressure and temperature or the presence of aqueous pore fluids (Nakajima et al., 2001).This high $\sigma$ ratio may have facilitated the process of brittle failure at depth by relaxing the seismogenic zones with the release of accumulated stress in metamorphic rocks. The seismic velocity profiles along the A-B C-D and E-F at depths of $5-10 \mathrm{~km}$ is conspicuously characterized by a low velocity zone, which is due to the presence of sedimentary sequences deposited in the marine environment. The vertical dispositions of both BT and OF are marked up to deeper layers through which a train of distinct low velocity zones emanates from the deeper layers towards the surface, which may have been behaving as a fluid on the time scale of deformation where earthquakes occur in the depth range of $35 \mathrm{~km}$ to $45 \mathrm{~km}$. We believe that our results are more authentic in sense that we analysed the data collected from dense seismic networks, which in turn provided an opportunity to conduct fine 3-D seismic imaging of the region. Our $\sigma$ estimates at these depth ranges also provide a good constraint on our interpretations. Furthermore, the OF is more or less flat at depth toward the aseismic semibrittle zone below the seismogenic layer (Figs. 3 - 5). Flatten in the mid crust region and detach at the top of the aseismogenic layer. Beneath the plateau, the thickness of the crust is over $\sim 45 \mathrm{~km}$ around the Moho, and a high velocity zone obviously exists. In comparison OF and DF have a strong impact on the velocity structures in the middle and lower crust. As the crust thickens beneath the plateau, pressure increases can trigger metamorphic reactions at lower crustal levels; in particular, evidence for transformation to eclogite in the Indian plate provides support for theories about mass transfer from the lithosphere to the underlying mantle (Henry et al., 1997; Beck and Zandt, 2002; Monsalve et al., 2008). The low $\sigma$, high conductivity and earthquakes are consistent with the presence of fluids with high pore pressure in highly fractured materials. As Lemonnier et al., 1999 suggest, fluids can originate from dehydration reactions in the Indian crust under thrusts beneath the Himalaya. In this study Moho configuration is clearly resolvable. The Moho configuration obtained by receiver function analysis for the study region varies between $38 \mathrm{~km}$ and $40 \mathrm{~km}$ (Mitra et al., 2005).

The plateau is characterized by positive Bouguer and isotstaic anomalies, which imply denser and thicker crust beneath the plateau (Verma et al., 1976). Several faults are encountered in the complexity zones. As a result, crustal structures are complicated, and strong lateral heterogeneity exists in the crust and upper mantle. It is also interesting to note that very few earthquakes are located in the depth range of 30-60 km, which mainly occurred in the high Poisson's ratio zone. This again suggests that earthquakes in this depth range are associated with ductile parts of underneath rock materials. We may interpret that the upper mantle materials act as jelly, as proposed in the "jelly sandwich" model of the seismogenic zone, which is anticipated by Chen and Molnar (1993) for continental crustal seismicity. Poisson's ratio $(\sigma)$ is more diagnostic of crustal and subcrustal rock properties and has a very close bearing on the seismogenic strengths and material properties of insitu rock beneath the study area and its adjoining areas. It is important to mention a high $\sigma$ suggests weak and less competent rock materials associated with fractures/cracks. The fractures and cracked volume of rocks in the tectonically complex zone may be partially or fully saturated at the subsurface layers, which require detailed geotectonic information about the area for compressive interpretation. 
The plateau is associated with several seismotectonic faults, which may have caused fracturization of underlying rocks. This region where the great 1897 Shillong earthquake occurred indicated that the earthquake in the region contributed to the relaxation of high ambient stresses were locally concentrated within rheological heterogeneities and the relatively competent and crystalline parts of rock materials beneath the study area. This region contains highly fractured and faulted granitic bodies at the surface (GSI, 2000). The Shillong Plateau may accommodate significant strain due to the compression of faults from all sides.

A closer examination of the distribution of the $\mathrm{P}$ - and $\mathrm{T}$-axes suggested that although the pattern seems quite variable, there is a consistent picture of an overall northeast and southwest compression reflecting a contraction with the Indian plate at a rate geodetically estimated to be $4 \pm 6 \mathrm{~mm} / \mathrm{yr}$ (Bilham and England, 2001). Fig. 6 shows a prevailing strike-slip environment in the Shillong region with both $P$ and Taxes oriented subhorizontally. The distribution in Fig. 7 also inferred a more variable pattern along the OF, $\mathrm{BF}$ and KF faults, perhaps owing to the strong heterogeneities along faults (Fig. 2a, b). The seismotectonic setting of the Shillong plateau is summarized in Fig. 7. The pop-up tectonics is confirmed by present seismic tomography study. This plateau shows high-velocity bodies $<40 \mathrm{~km}$ depth where $76 \%$ seismicity is observed, indicating a seismogenic zone. The brittle behaviour is thicker in this area than what is observed by many researchers in other parts of NE India.

Detailed information on subsurface structures is essentially required as inputs for evolving a comprehensive model for earthquake risk mitigation for a region. The generation of a shallow crustal earthquake could be controlled by a deep process in the lower crust and upper mantle. From this point of view, it is vital to investigate the detailed structure and processes of the lower crust and upper mantle to clarify the seismogenesis and reduce earthquake risk. It is insufficient to refer only to the surface description of spatial features to predict the seismic potential of a region. Large damaging earthquakes occurred in décollement zones that leave very little surface evidence of faulting that can be used to identify past earthquakes. We infer that the use of detailed 3-D seismic tomography may offer potential information on Pop - Up tectonics beneath the Shillong Plateau to unravel what and how the genesis of such large damaging earthquakes caused. This study may help in evolving a comprehensive earthquake hazard mitigation model for a region.

We present robust P- and S-seismic wave velocity images of the Shillong Plateau, which shed important insight into the seismogenic and rheological behaviours of the study region. The uppermost crust is clearly revealed as a low $\mathrm{V}$ and low $\mathrm{Vp} / \mathrm{Vs}$ layer down to a depth of $10 \mathrm{~km}$ due to fractures and cracks and the low permeability of the layer. The geological faults are well imaged in the cross sections. The DF fault northwards and is associated with high-velocity zones. We noticed a high velocity at the depth of 20-38 km. The thickened crust across the collision zone could be associated with a pressure increase that can trigger metamorphic reactions at lower crustal levels. It is inferred that some zones appear favourable to accumulate differential strain due to the prevalence of contrasting velocity and $\mathrm{Vp} / \mathrm{Vs}$ ratio at the boundary layers, which can generate micro earthquakes once the shearing strength of rocks is suppressed by the differential stain accumulation. 


\section{Methods}

To understand the seismicity pattern in the active part of the Shillong Plateau, this is still poorly instrumented to obtain detailed seismological investigation. A Geological Survey of India (GSI) conducted earthquake monitoring from March 2010 to February 2013 by setting up a total of 11 temporary 3component digital broadband seismographs in a network (Fig. 1). Among which, a total of three shortperiod seismographs with 3-components were also installed for precise detection of direct P-and S-arrival times of earthquakes that occurred within $25-30 \mathrm{~km}$. The seismographs were operated by a rechargeable 12-volt power-safe battery of 100 amperes per hour associated with an inbuilt GPS to obtain precise locations of seismographs with the reference time of the event. The phases that complied in the monthly seismological bulletin of the NCS data recorded at 5 permanent broadband seismic stations from March 2010-December 2014 were also used in this study. The present analysis is based on the acquisition of seismological data through the campaign mode and permanent stations. All seismic stations were equipped with a three-component seismograph. These stations recorded $40-100$ samples per second. As shown in Fig. 1, this seismic network consists of 16 seismographs covering the whole Shillong Plateau. The picking accuracy of arrival times is estimated to be $\sim 0.03-0.12 \mathrm{~s}$ for the P-waves and $0.06-0.22$ s for the S-waves. Between March 2010 and December 2014, a total of 1000 events with magnitude $M \geq 1.8$ were recorded by temporary and permanent seismic networks of the Shillong region. We employed the HYPO71 algorithm (Lee and Lahr, 1975) to determine the locations of the events. The located events with root mean square error $(\mathrm{rms}) \leq 0.2$, horizontal error $\leq 1.5 \mathrm{~km}$, vertical error $\leq 2.5 \mathrm{~km}$ a minimum of 4-S arrival times to better constrain the depth. These databases have been scanned with two main criteria an event recorded by at least four seismic stations with four reliable P-phases and at least two reliable S-phases are considered. Second, the initial locations of the events are located with rms $\leq 0.1 \mathrm{~s}$. This procedure reduced the dataset to 670 events, including $3798 \mathrm{P}$ - and $3567 \mathrm{~S}$-waves, which were used for simultaneous inversion. Sample seismograms of earthquake recorded by seismic stations of a temporary network in the Shillong region is shown in Fig. 8. The ray tracing of events at different depths and depths are depicted in Fig. 8. We tested different available velocity models (De and Kayal, 1990; Mukhopadhyay et al., 1997; Mishra et al., 2004, 2011; Bhattacharya et al., 2008). Finally, we selected the Mishra et al., 2011 model based on residuals. We show the ray sampling plot for the local earthquake tomography (LET) at different depths and depths in Figs. $8 a$ and $b$.

We employed the 3-D tomographic technique of Zhao et al. (1992) to determine the 3-D velocity structures of the Shillong Plateau in the present study. It is an iterative algorithm for simultaneous inversion of $\mathrm{P}$ - and S-arrival times from local and regional events resulting in three-dimensional distributions of seismic velocities $\left(V_{P}\right.$ and $\left.V_{S}\right)$ and source coordinates. According to the ray density distribution, we parameterized this study volume using a grid of node distributions, following the Zhao et al. (1992) algorithm. To calculate ray paths and arrival times precisely and rapidly, the efficient 3-D ray tracing algorithm of Zhao et al. (1992) is applied that iteratively uses the pseudo bending method of Um and Thurber (1987) and Snell's law to search the fastest ray from an initial estimate of the ray path. We used some events outside of the network, which could significantly improve the results of local 
earthquake tomography (Zhao et al., 1994). To avoid large model variations, a suitable damping parameter is selected for the diagonal elements of the separated medium matrix that results in near-zero singular values. We selected the damping parameter by conducting a series of iterative inversions using a large range of damping values based on studies performed by other researchers using the 3-D tomographic method (Eberhart-Phillips and Michael, 1993). The norm of solutions (\%) versus rms travel time residual to select a damping parameter of 10 for P-and S-wave velocity in this study. The selected value of damping has shown reasonable control on estimated velocity anomalies that minimize the influence of seismic noise in the data.

\section{Resolutions Tests}

We rigorously conducted checkerboard resolution tests for both $V p$-and $V s$ - seismic structures using the checkerboard resolution test method of Zhao et al. (1992), originally derived from Humphreys and Clayton (1988) and Inoue et al. (1990), to examine the spatial resolution of the present dataset. We have done a series of the checkerboard tests. We included Fig. 9 in support of the resolution of our dataset and assimilated tomograms with Indeed. The results of these tests have shown that anomalies smaller than $10 \mathrm{~km}$ can only be resolved in the study area where most seismicity and seismic stations are located. In most parts of the study area, such anomalies are strongly replotted due to the dominance of orientations of seismic rays due to the enhancement of crisscrosses along seismic rays between sources to receivers. However, for anomalies of $15 \mathrm{~km}$ size, the situation improves. Finally, anomalies of $15 \mathrm{~km}$ size are robustly resolved throughout the study area. This test allows us to distinguish the anomalies by size and location and helps us to estimate which of them are robust. Based on these tests, we defined the resolved area; outside, the resulting anomalies were masked. The resolution test with a grid spacing of $15 \mathrm{~km}$ indicates good resolution for both Vp and Vs anomalies beneath the Shillong Plateau. The checkerboard resolution tests for both Vp and Vs are shown in Figs. 9a, b. This test is carried out to assess the resolvability of data used in assimilating the velocity structures beneath the study area for the given model parameterization and it also helps to understand how much recovery of current velocity anomalies is possible within the model for given grid spacing set up for both lateral and vertical directions. This test allows us to distinguish the anomalies by size and location and helps us to estimate which of them are robust. Based on these tests, we defined the resolved area; outside, the resulting anomalies were masked. The tomograms are assimilated for different depth slice for Vp-and Vs structures. We tested our dataset for different grid spacings in both the lateral and vertical directions of the model space by keeping the preamble of resolution, as the grid spacing should be smaller than the minimum resolved size of velocity anomalies at every pixel (Figs. 9a, b). We found that our 3-D seismic tomograms (Vp, Vs, $\sigma)$ are well resolved for the grid setup.

We provided both positive and negative velocity perturbations with a $5 \%$ anomaly alternatively to the grid nodes in the entire 3-D grid setup. We achieved the results of the checkerboard resolution test (CRT) at the different representative layers for Vp and Vs as shown in Figs. 9a-b. The CRT is found to recover $3 \%$ of anomalies for most of the layers except for the edge part of the study area, which has less crisscross 
among seismic rays for the given model parameterization. We conducted a series of synthetic tests with different sizes of anomalies. Based on the recovery results, we defined a zone with satisfactory resolution. In this presentation, the main results of the tomography inversion are shown by masking edge portions.

\section{Declarations}

\section{Acknowledgement}

OPM is thankful to the Geological Survey of India for all support and encouragement during the field investigations conducted in the Shillong area. The authors are grateful to the Secretary Ministry of Earth Sciences for providing an encouraging academic environment to conduct extensive analysis at its National Centre for Seismology.

\section{Data and Resources}

We used seismic waveform data recorded during the period 2007-2009 by the seismographic network ascribed to the Geological Survey of India. Some figures were prepared using the public domain GMT software (Wessel and Smith, 1998).

\section{Competing interests}

The authors declare no competing interests

\section{References}

1. Ben-Menahem, A., Aboudi, E. and Schild, R. (1974) The source of the great Assam earthquake an intraplate wedge motion. Phys. Earth Planet. Int., 16, 109-131.

2. Bhattacharya, P. M., S. Mukhopadhyay, R. K. Majumdar, and J. R. Kayal (2008), 3-D seismic structure of the northeast India region and its implications for local and regional tectonics, J. Asian Earth Sci., 33(1-2), 25-41.

3. Bilham, R. and England, P. (2001) Plateau pop-up during the 1897 Assam earthquake Nature, 410, 808-809.

4. De, R, Kayal, J.R., (1990). Crustal P - wave velocity and velocity ratio study in northeast India by a microearthquake survey, Pure and Applied Geophysics. 134, 93-108.

5. De, Reena and J. R. Kayal (1990). Crustal P-wave velocity and velocityratio study in northeast India by a microearthquake survey, Pure Appl. Geophys. 134, 93-108.

6. Eberhart - Phillips, D., and S. Bannister (2002). Three-dimensional crustal structure in the southern Alps region of New Zealand from inversion of local earthquake and active source data, J. Geophys. 
Res. 107, no. B10, 2262, doi: 10.1029/2001JB000567.

7. Evans, P., 1964. The tectonic frame work of Assam, J. Geological Society India, 5, 80-96

8. Gahalaut, V. K., Shikha Rajput and Kundu, B., 2011, Low seismicity in Bhutan Himalaya and the 1897 Shillong Plateau earthquake. Physics Earth Planetary Interiors, v. 186, pp. 97-102. doi:10.1016/j.pepi.2011.04.009.

9. Gahalaut, V.K. and Kundu, B., 2012, Possible influence of subducting ridges on the Himalayan arc and on the ruptures of great and major Himalayan earthquakes. Gondwana Research, v. 21, pp.1080-1088, doi:10.1016/ j.gr.2011.07.021.

10. Govin, G., Najman, Y., Najman, Copley, A., Millar, I., van der Beek, P., Huyghe, P., Grujic, D., Davenport, J. (2018) Timing and mechanism of the rise of the Shillong Plateau in the Himalayan foreland, Geology 46(3):279-282

11. Holt, W. E., Ni, J.F., Wallace, T. C. and Haines, A.J., 1991, The active tectonics of the eastern Himalayan syntaxis and surrounding regions. Journal of Geophysical Research, 96, pp. 1459514632

12. Humphreys E, Clayton R (1988) Adoption of back projection tomography to seismic travel time problems, J Geophys Res 93, 1073 - 1085

13. Inoue, H., Fukao, Y., Tanabe, K., Ogata, Y., 1990. Whole mantle P wave travel tomography. Phys. Earth Planet. Inter. 59:294-328,

14. Kayal, J. R., S. S. Arefiev, S. Baruah, D. Hazarika, N. Gogoi, J. L. Gautam, S. Baruah, C. Dorbath, and R. Tatevossian (2012), Large and great earthquakes in the Shillong Plateau-Assam valley area of northeast India region: Pop-up and transverse tectonics, Tectonophysics, 532-535, 186-192

15. Kayal, J. R.., Zhao, D. (1998) Three -Dimensional seismic structure beneath Shillong Plateau and Assam Valley, Northeast India, Bulletin of Seismological Society America, 88(3), 667-676

16. Lee, W., Lahr, J., 1975. HYP071 (revised): A Computer Program for Determining Hypocenter, Magnitude, and First Motion Pattern of Local Earthquakes. US: Geol Surv: Open-File-Report 75-311, pp. 114.

17. Mishra O. P., G. K. Chakrabortty, K. K. Mukherjee, O. P. Singh, M. B. Mahadeva, A. Selin Raj, (2013) A report on Detailed Seismological Study of the Shillong Plateau and Its Adjoining Areas (Code: SEl/CHQ/CGD/2009-044) Field Season: 2009-10 \& 2012-13, pp. 73

18. Mishra, O. P., 2004. Lithospheric heterogeneity and seismotectonics of northeast Japan and Indian regions. Unpublished D. Sc. Thesis, Ehime University, Japan, 223

19. Mishra, O. P., 2011. Three-dimensional tomography of NE India and Indo-Burma region and its implications for earthquake risks. Workshop volume on Earthquake Risk Mitigation Strategy in NE. NIDM-AASC, 40-54.

20. Mukhopadhyay, S., R. Chander, and K. N. Khattri (1997), Crustal properties in the epicentral tract of the great 1897 Assam earthquake, North-eastern India, Tectonophysics, 283(1-4), 311-330.

21. Oldham, R. D. 1899. Report on the great earthquake of 12 June 1897. Mem. Geolo. Surv. Ind, $29,397$. 
22. Rao, M. B. R. (editor), 1953. A compilation of papers on the Assam earthquake of August 15, 1950. The Central Board of Geophysics, Government of India.

23. Seeber L. and Armbruster, J. (1981) Great Detachment earthquakes along the Himalayan Arc and long-term forecasting. In: D.W. Simpson and P.G. Richards (Eds.), Earthquake Prediction - An international Review. Maurice Ewing Series. Amer. Geophys. Union, v.4, pp.259-277.

24. Um, J. and C. Thurber (1987). A fast algorithm for two-point seismic ray tracing, Bull. Seism. Soc. Am. 77, 972-986.

25. Verma R. K., Mukhopadhyay, M., and Ahluwalia, M. S. 1976, Seismicity, gravity and tectonics of northeast India and northern Burma, Bull. Seim. Soc. Am., 66, 1683-1694.

26. Wessel, P., Smith, W.H.F., 1998. New, improved version of the generic mapping tools released. EOS Trans. AGU 79, 579.

27. Zhao, D., Hasegawa, A., Horiuchi, S., 1992.Tomographic imagining of $P$ and $S$ wave velocity structure beneath northeastern Japan. J. Geophys. Res. 97, 19909-19928.

28. Zhao, D., Hasegawa, A., Kanamori, H., 1994. Deep structure of Japan subduction zoneas derived from local, regional and teleseismic events. J. Geophys. Res. 99, 22313-22329.

29. Zhao, D., Mishra, O. P., Sanda, R., 2002. Influence of fluids and magma on earthquakes: seismological evidence. Phys. Earth Planet. Inter. 132:249-267.

\section{Figures}




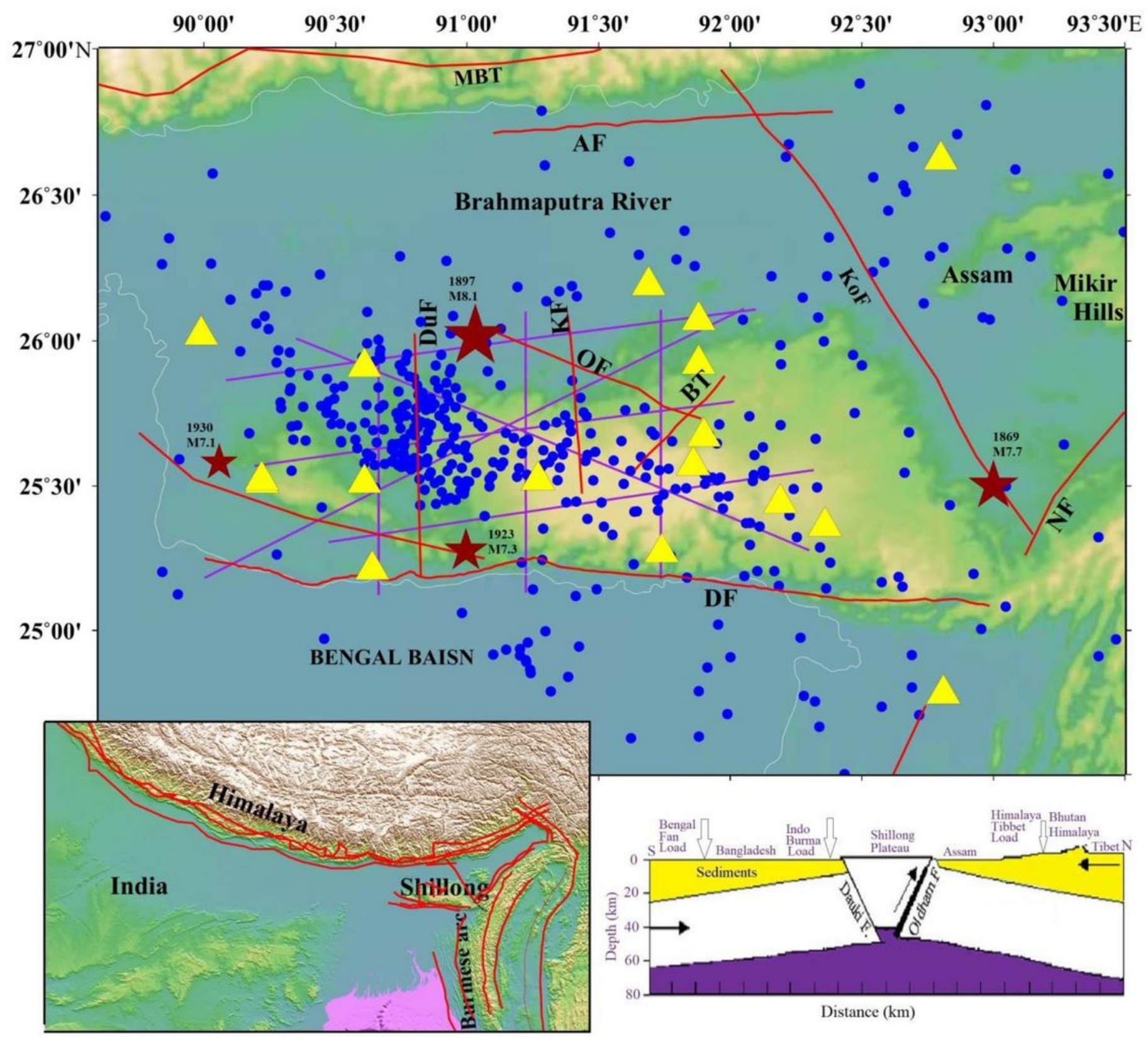

Figure 1

Topographic map of the Shillong Plateau showing major earthquakes (stars) $M \geq 7.0$ including an 1897 great ( $M$ 8.7) earthquake. The major tectonic features are also shown, such as DF: Dauki Fault; DT: DapsiThrust; OF: Oldham Fault; DuF: Dudhani Fault; KF: Kulsi Fault; BT: Barapani Thrust; NF: Naga Fault; KoF: Kopili Fault. Blue triangles show the seismic station while black solid circles show the seismicity, used in the present study. Inset the location of the Shillong and left map of the N-S section from Tibet to the Bay of Bengal showing the geometry of the plateau pop-up tectonic model (After Bilham and England, 2001). 

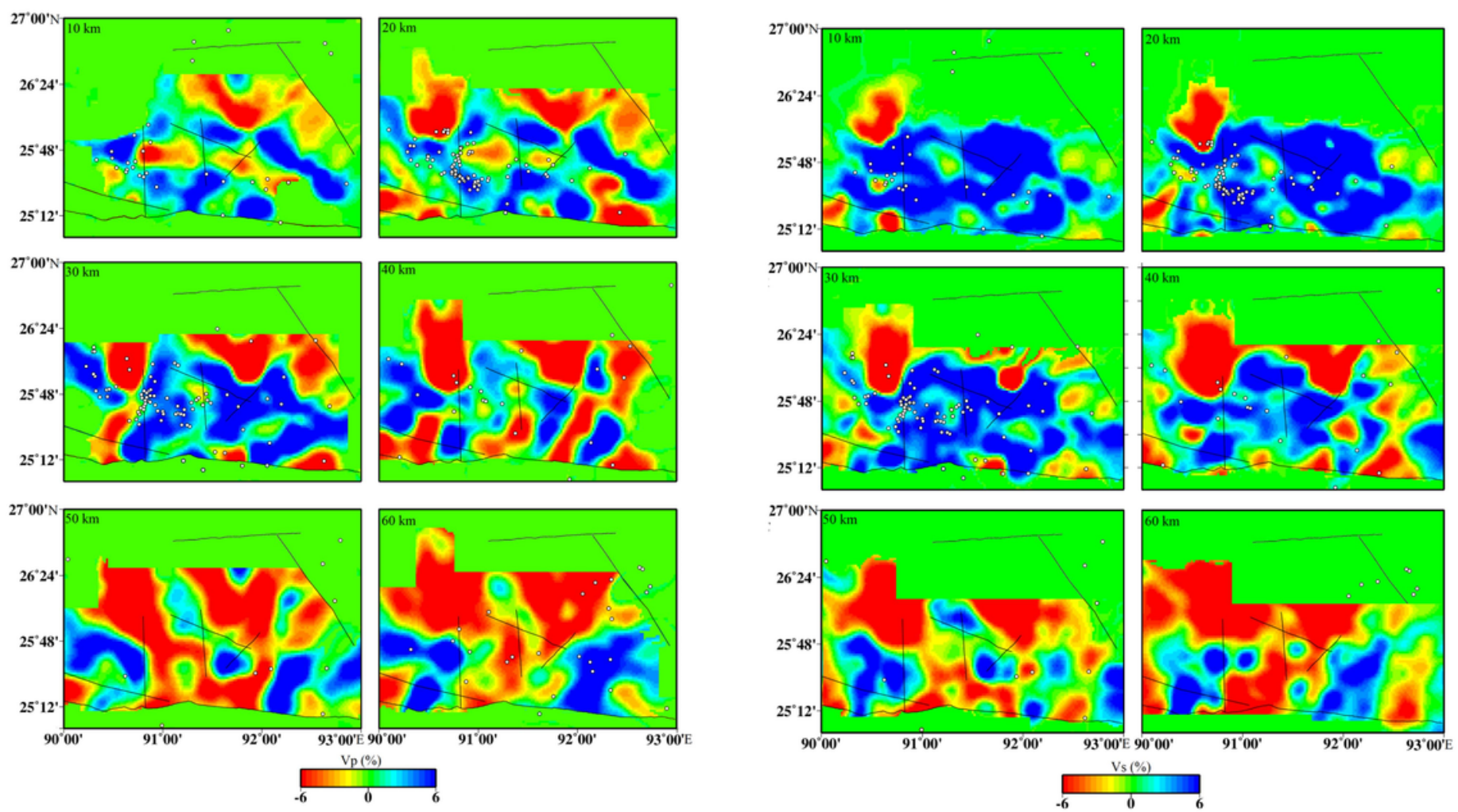

\section{Figure 2}

a: Maps showing the perturbation of P-wave velocity in \% at different depth levels such as $10 \mathrm{~km}, 20 \mathrm{~km}$, $30 \mathrm{~km}, 40 \mathrm{~km}, 50 \mathrm{~km}$, and $60 \mathrm{~km}$. The layer depth is indicated on the left side of each map, and the thin lines depict the faults and lineaments. The dots indicate the earthquakes.

b: Same as Fig. 5a but for S-wave velocity. 

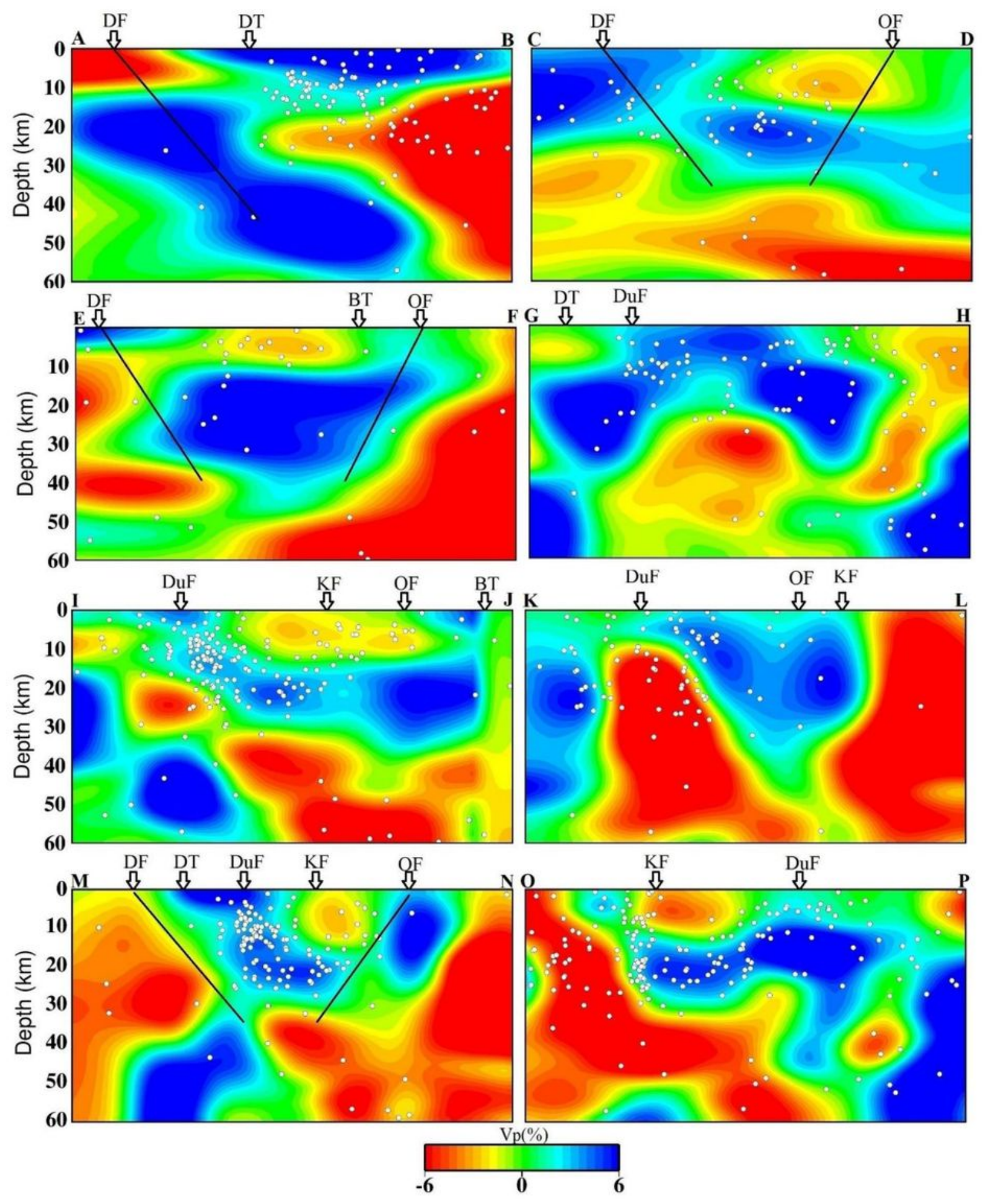

Figure 3

Vertical cross sections of the P- wave velocity models. The positions of the cross sections are shown in Figure 1.The geological faults are also marked. 

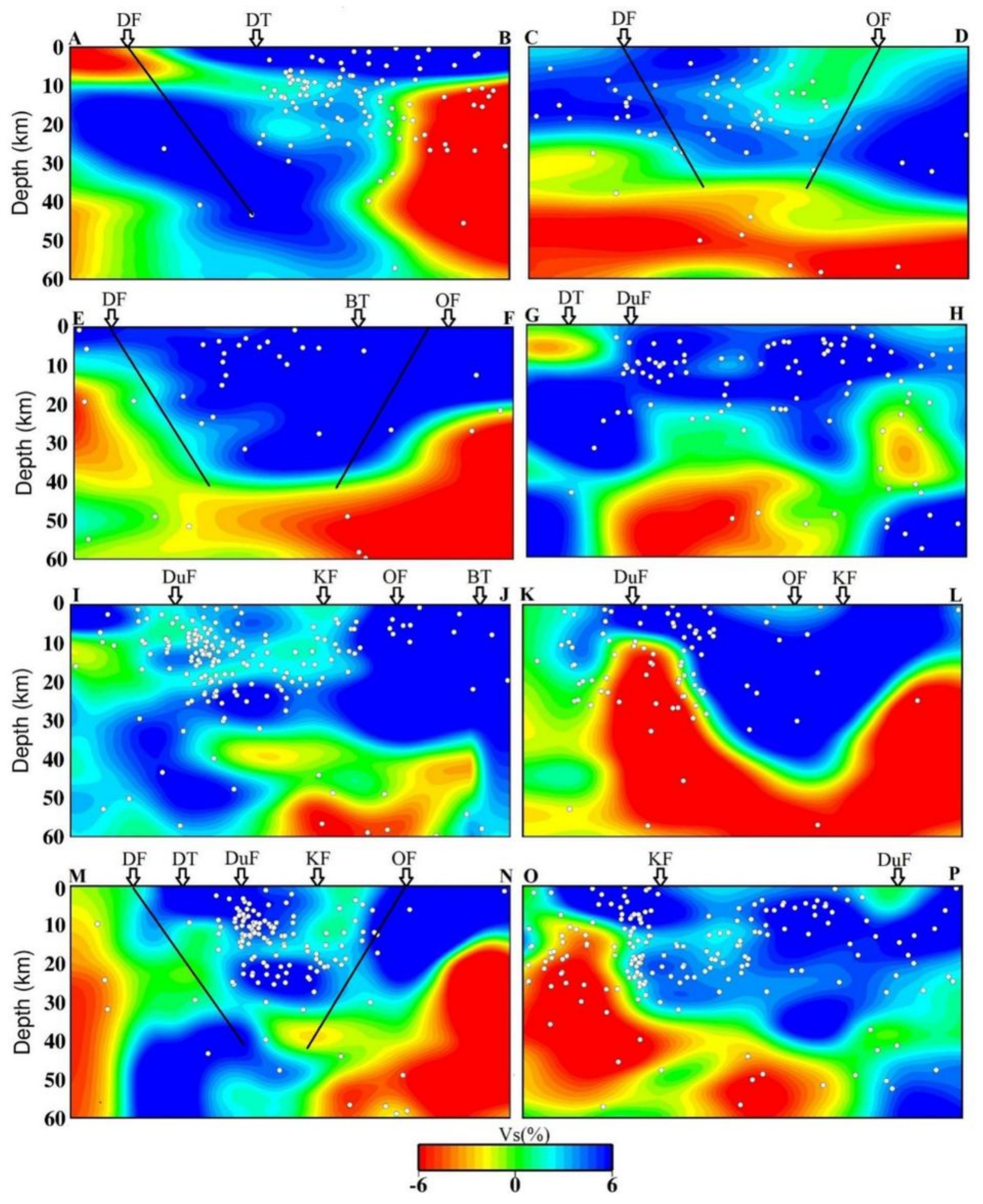

Figure 4

Vertical cross sections of the S- wave velocity models. The positions of cross sections are shown in Figure 1. The geological fault is also marked 

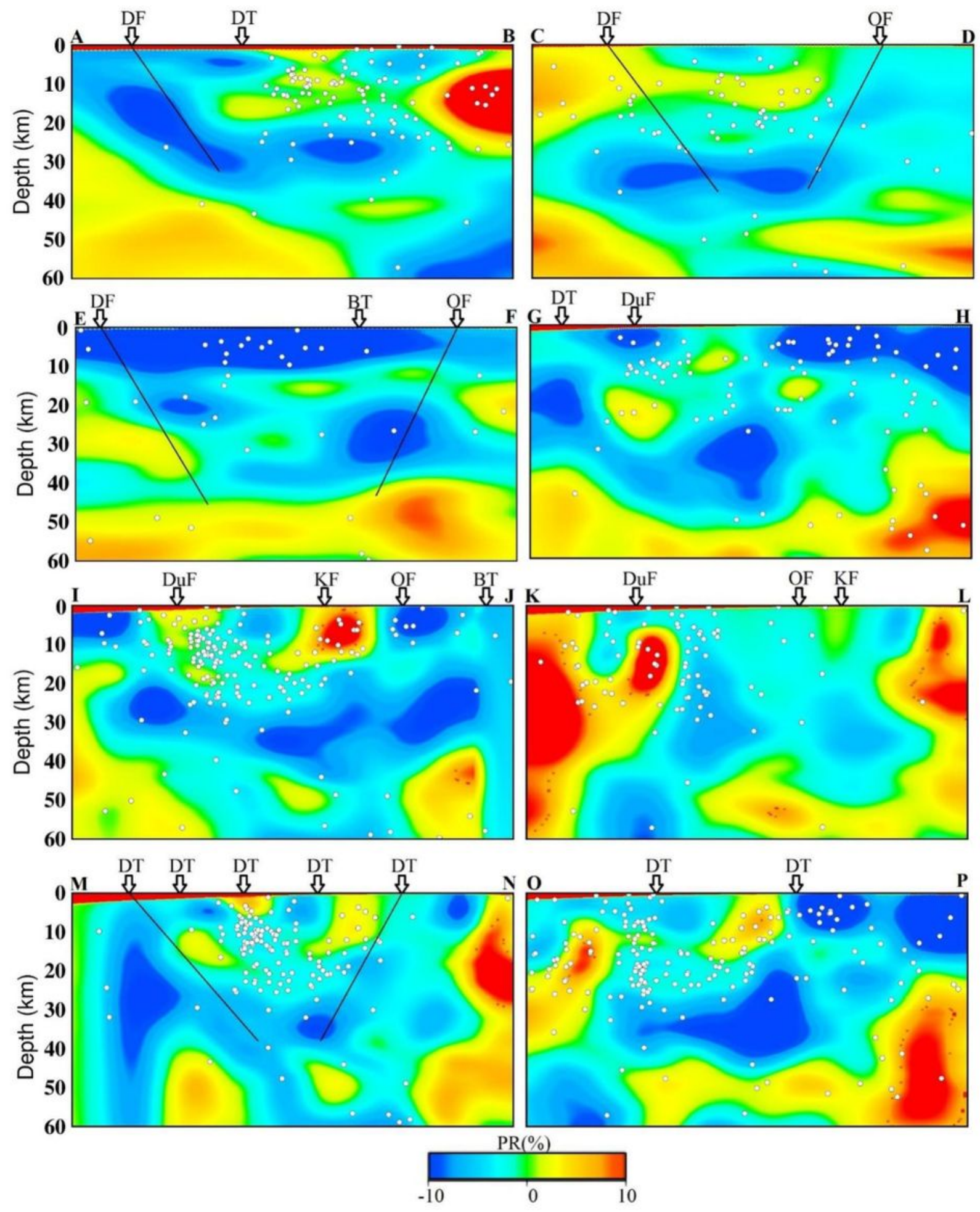

Figure 5

Vertical cross sections of the $\sigma$ models. The positions of cross sections are shown in Figure 1. The geological fault is also marked 


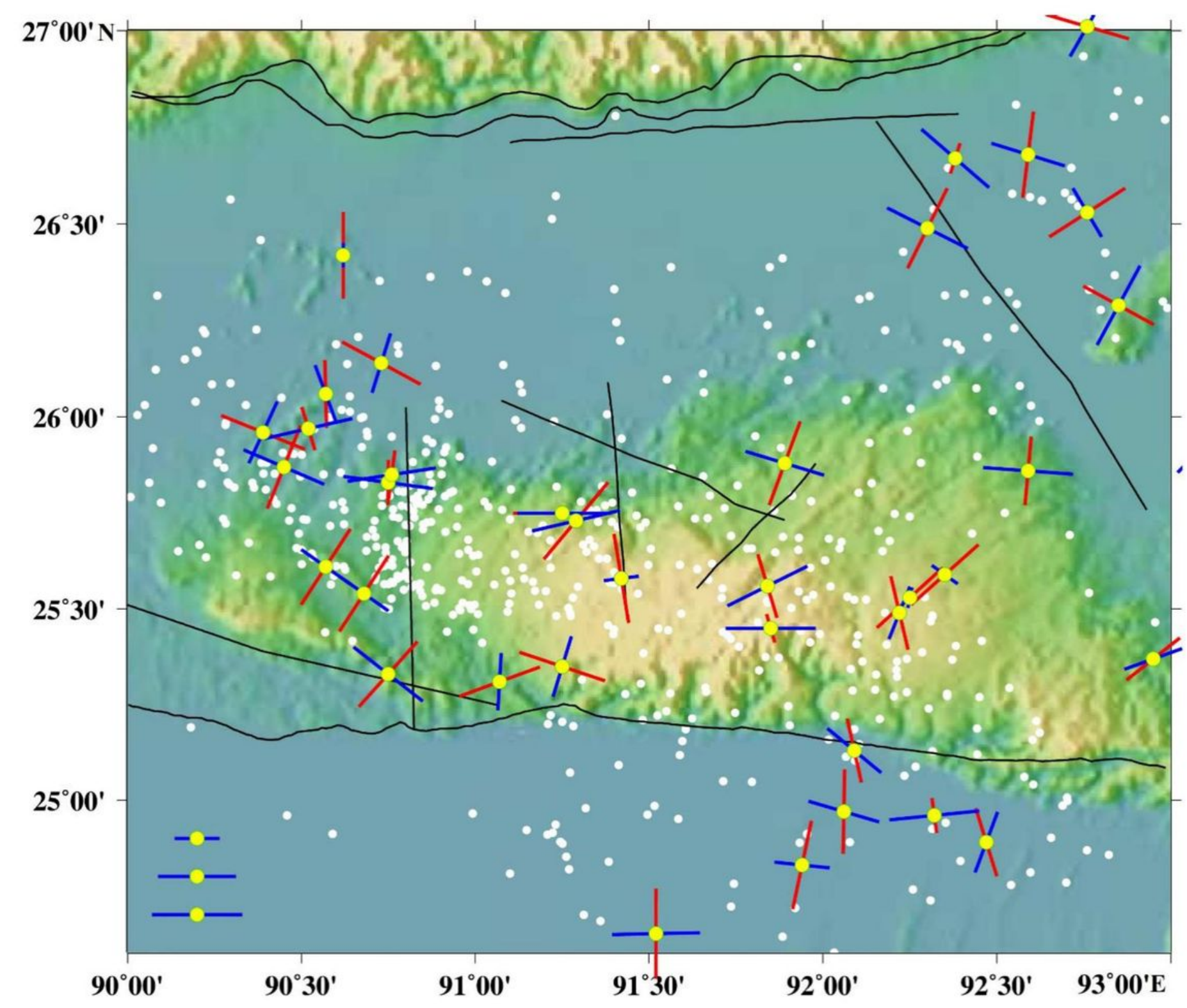

Figure 6

Horizontal projections of the P-and T axes of the 41 available focal mechanism solutions. Red and blue line segments are for the P- and T-axes, respectively, and the yellow dots are epicentral locations. The length of each projection is determined by the plunge of the axis, with the maximum length corresponding to a plunge angle of $0^{\circ}$, i.e., a horizontal axis. Black lines are major faults as introduced in Fig. 1. White circles show seismicity in the Shillong Plateau. 


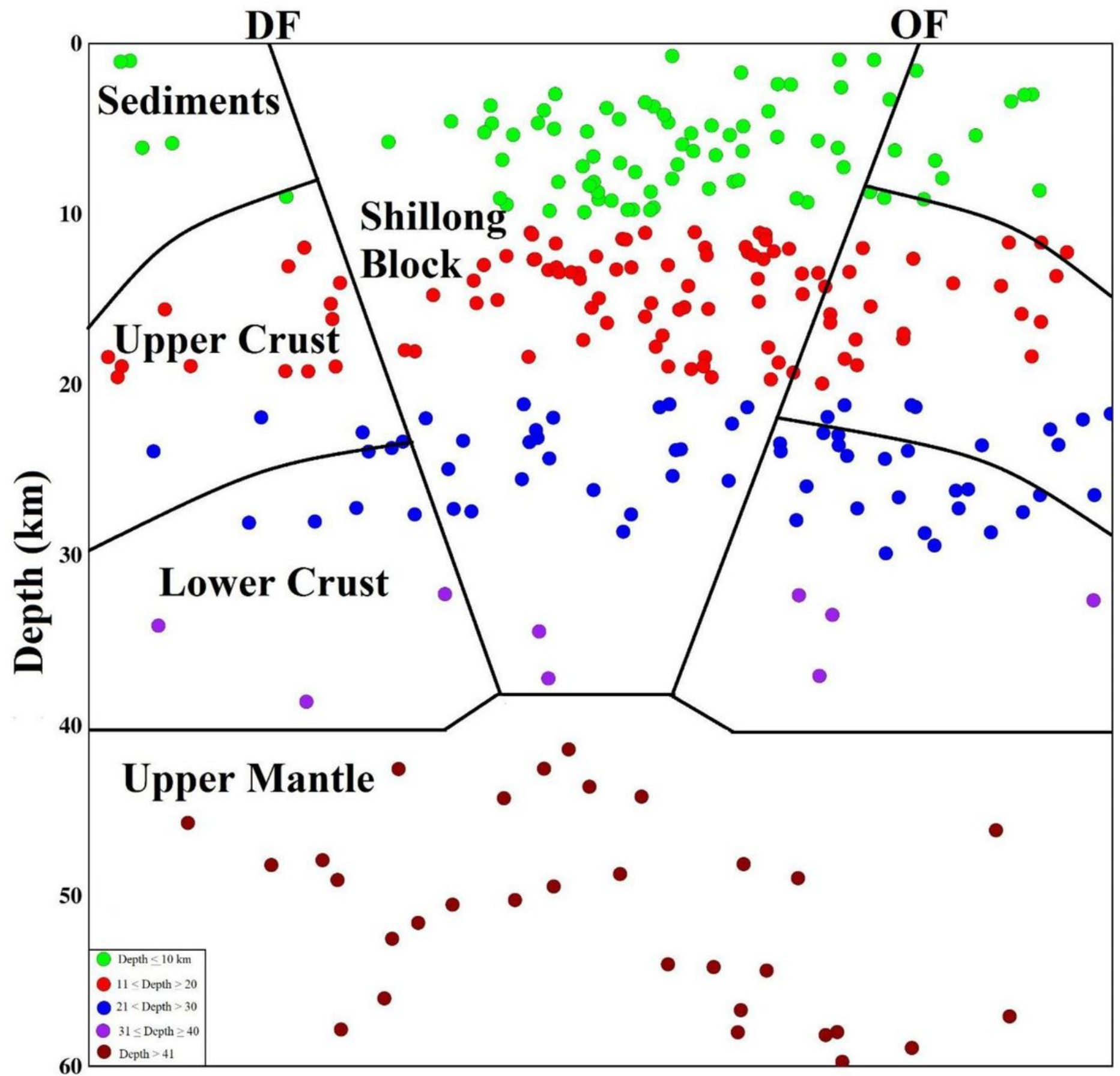

Figure 7

Seismotectonic scenario of the Shillong Plateau, Northeast India region. Brown colours show the sediments, while grey colours indicate uppermost mantle. Yellow circles are the relocated earthquake locations from the present study. The rate of convergence of the Indian plate (in $\mathrm{mm} / \mathrm{yr}$ ) is extracted from Vernant et al. (2014). 

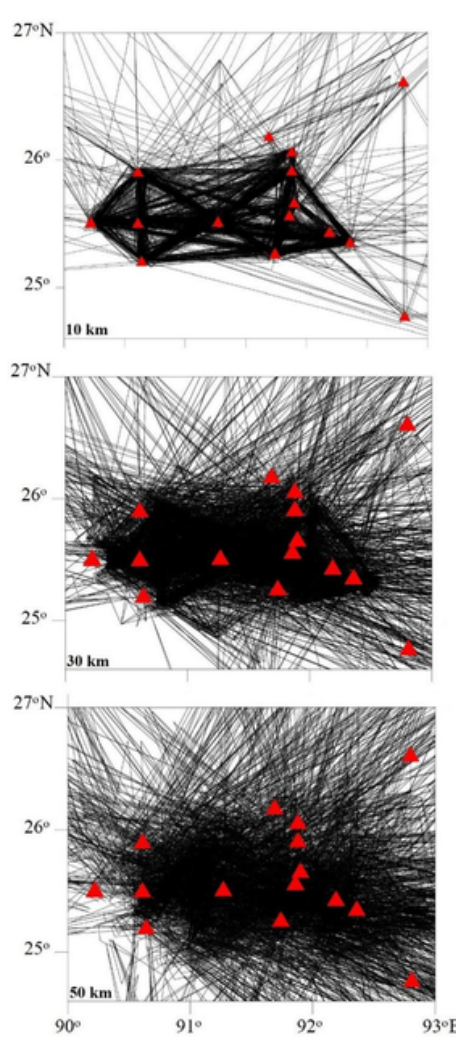
$93^{\circ} \mathrm{E} \quad 90^{\circ}$
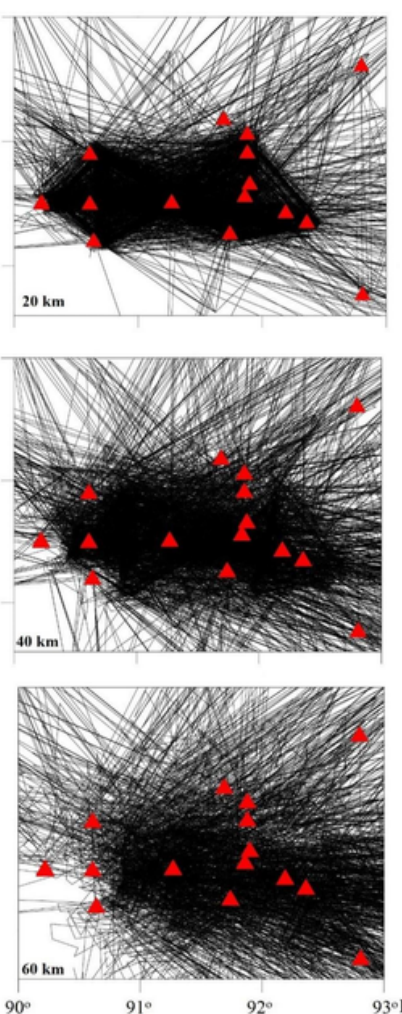
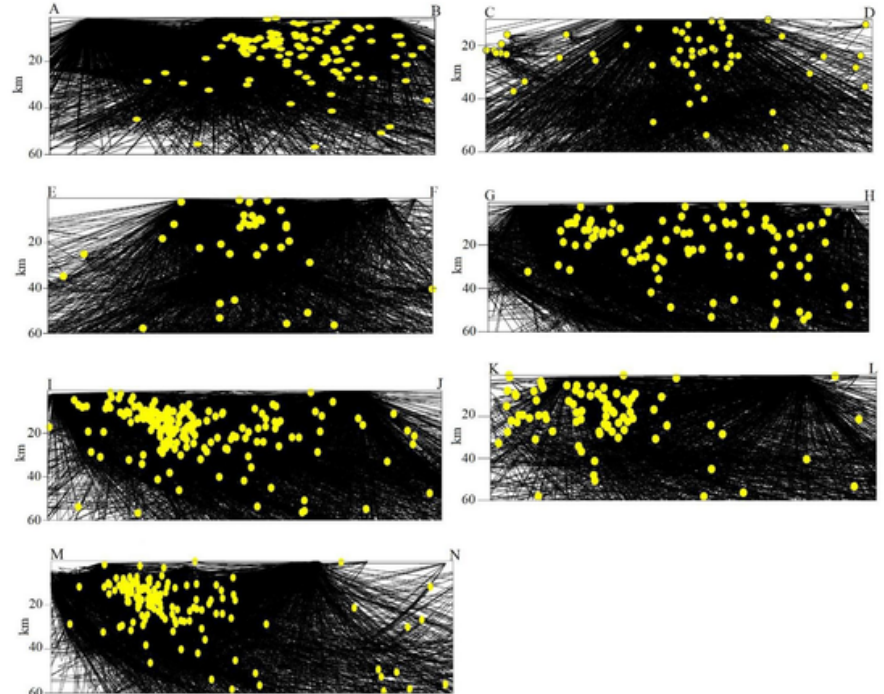

\section{Figure 8}

a: Maps show the crisscross at various depths. The soild circles indicate the distribution of events. The distribution of seismic stations (triangles) is also shown.

b: Maps show the depthwise crisscross. The solid cicles depict ditrsibution of events. The positions of cross-sections are given in Fig.1. 

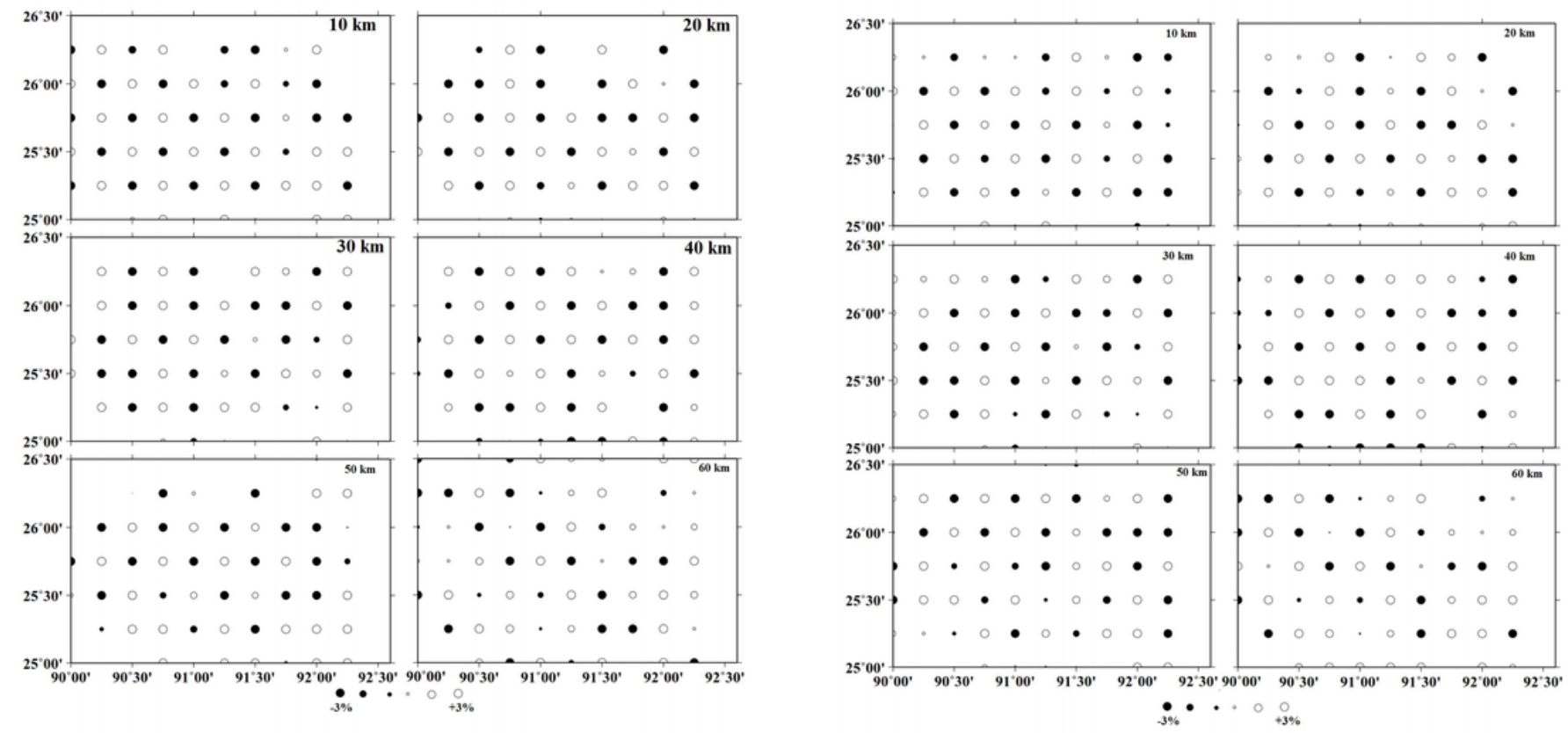

\section{Figure 9}

a: The results of the checkerboard resolution test for P-wave velocity at six depths. Black and white circles denote low and high velocities, respectively. The perturbation scale is shown at the bottom.

b: The results of the checkerboard resolution test for S-wave velocity at six depths. Black and white circles denote low and high velocities, respectively. The perturbation scale is shown at the bottom. 